\title{
LA SIMBOLIZACIÓN DEL VALOR
}

\author{
La demostración se basa en nocio- \\ nes, no en notaciones.
}

Karl Friedricil Gauss

\section{La transposición entre sistema sintético y realidad analítica}

Là tesis de las siguientes observaciones es que la simbolización de los juicios de valor es ilegítima a menos de que ocurra dentro de un sistema aplicable a una realidad sistematizada: a menos de que haya correspondencia metodológica entre el sistema y el campo de su aplicación. Según nuestra tesis no es válida la aplicación de un simbolismo a una realidạd que no ha sido preparada de antemano para tal aplicación. $O$, con otras palabras, no es válido ningún sistema que no sea el resultado de un estudio exhaustivo y a fondo de un campo de fenómenos, de manera tal que el meollo de este campo se formule en términos de un axioma. Por axioma entendemos no cualquier enunciado basado en cualidades secundàias del campo en cuestión, sino el resultado formalizado que se basa en las cualidades primarias de dicho campo.1

Un axioma es, pues, una fórmula que da origen a un sistema aplicable a una realidad que consiste en cualidades primarias y no secundarias, y que se explica por conceptos sintéticos y no analíticos. ${ }^{2}$ Los conceptos sintéticos son, precisamente, los términos del sistema en cuestión; los conceptos analíticos son abstracciones del sentido común. ${ }^{3}$ Los conceptos sintéticos se aplican a cualidades primarias; los conceptos analíticos se refieren a cualidades secundarias." Cualquier sistema de deducciones supuestamente "axiomáticas" o "lógicas" que se basa en propiedades secundarias de la materia no es, en consecuencia, más que la transposición de un sistema sintético a un material analítico. Semejante transposición es una simbolización ilegítima del campo en cuestión.

Como un ejemplo de semejante simbolización ilegítima en el campo de la valoración, el presente ensayo discute la teoría del valor de Everett $W$.

1 Para la diferencia entre propiedades primarias y secundarias, la importancia fundamental de esta distinción en la estructura de una ciencia, y en particular de una ciencia axiológica, véase Robert S. Hartman, La estructura del valor, Fondo de Cultura Económica, México y Buenos Aires, 1959, págs. 216, 266, 270, 273, 290.

2 Para la naturaleza del axioma véase Robert S. Hartman, op. cit., págs. 17, $655 s$, 7o s., $76,117,125,142$ s., 148 .

3 Para esta diferencia véase op. cit., págs. $5^{8 s s .,} 119$ ss.

4 Véase op. cit., pág. 105. 
Hall, especialmente como se encuentra expuesta en su importante libro ¿̇Qué es el Valor? 5 El procedimiento de Hall será comparado y confrontado con el procedimiento para simbolizar el valor que el autor expone en su libro $L a$ Estructura del Valor. Sin embargo, el argumento del presente ensayo es válido para cualquier teoría general del valor -o teoría especifica del valor, tal como una ética- que pretenda presentarse como ciencia sin haber penetrado el núcleo del campo fenoménico del valor y sin haber logrado definir las cualidades primarias del campo. Es válido, en otras palabras, para cualquier teoría del valor, o ética, que combine una estructura simbólica con material del sentido común: quèe construya un edificio supuestamente'científico sobre la base de una o algunas cualidades secundarias del valor - tales como el deseo, la preferencia, la satisfacción, etc. En su base misma semejante teoría no solamente comete una transposición metodológica sino que incurre también en el error lógico que George E. Moore ha llamado "la falacia naturalista": confunde el género de valor con una de sus especies.

Hall no comete esta falacia tan obviamente como otros axiólogos, o éticos, pretendidamente científicos, ${ }^{6}$ sino de una manera mucho más sutil; y ésta es la razón por la cual hemos escogido esta obra en lugar de otra, para comentarla en las páginas que siguen.

El razonamiento científico es tanto formal como material, teórico como práctico. Los dos aspectos de la ciencia no deben separarse, so pena de violar la estructura orgánica de la ciencia. Pues la razón teórica no tiene base sin el fundamento empírico, y el fundamento empírico no tiene organización sin la razón teórica. El alcance teórico y el empírico van juntos. Así, pues, el separar uno $u$ otro aspecto de la actividad científica ý relacionarlo -no con el otro aspecto, sino con alguna tercera entidad extraña, p. ej. el material no-científico del pensamiento analítico o del sentido común-, es como transformar cuerpos y cabezas. El resultado ha de ser con más probabilidad una monstruosidad que la divertida solución de la narración de Thomas Mann. En otras palabras, no se puedé tomar sencillamente una fase de la oscilación que es la ciencia y aplicarla al alambre. El resultado no será una corriente, sino un apagón.

Sucede que algunos experimentos de ese tipo se llevan a cabo en la teoría moral de nuestros dias. Están basădos en las concepciones empíricas defectuosas -wittgensteinianas y otras- las cuales, en lugar de penetrar hasta la médula de la experiencia moral, como lo haría el verdadero empírico, dan por sentado lo que la gente dice, a base del sentido común, acerca del valor, y aplican a este material de sentido común los procedimientos de 1952.

5 What Is Value? An Essai in Philosophical Analysis, Humanities Press, New York,

6 Como Davidson-McKinsey-Suppes, Outlines of a Formal Theory of Value. Report No. $I$, Stanford University, 1954, o Mario Bunge, Etica y ciencia, Siglo Veinte, Buenos Aires, 1960 . 
la ciencia teórico-empírica; ya sea "teóricamente", mediante la formulación de un simbolismo que se supone da razón de este material, o bien "empíricamente", aplicando al material métodos estadísticos tales como la gradación, la medición por escala, la clasificación, etc., 7 y proclamando los resultados como una comprensión profunda, no de la frecuencia de las ocurrencias, sino del significado del fenómeno sobre el cual habla la gente y que se supone ser lo que la gente piensa que es: jcomo si Galileo, al investigar el fenómeno del movimiento, hubiese organizado una encuesta y tabulado las respuestas para obtener una comprensión profunda del fenómeno de la mecánica!

El resultado de tales procedimientos, ya sea "teórico" o "empírico", no puede ser sino seudo-científico; pues si la ciencia è la combinación, la vinculación, entre teoría y práctica, entonces es anti-científico, y en verdad no tiene sentido, aplicar la forma simbólica al contenido de sentido común o producir una teoría estadística o similar a partir de éste. El material del sentido común y sus conceptos analíticos pueden servir solamente como escalones para nuevas teorías sintéticas, y deben ser descartados y reemplazados por la extensión sintética tan pronto como la teoría sea creada. Combinar en principio la extensión analítica y la comprehensión sintética, y llamar a esta combinación una nueva ciencia o una nueva lógica, es igual que llamar a un centauro caballo de carreras o sabio. El único contenido legítimo de la teoría científica es la realidad sintética correspondiente. ${ }^{8}$ Allí donde no hay tal realidad y se usa el viejo material del sentido común como contenido, tenemos una seudo-forma con un seudo-contenido, metodológicamente idéntico al de los alquimistas, que usaban una seudo-forma, tal como los números pitagóricos, y la aplicaban al seudo-material -mejunjes de todas clases: un cabello asado con cebolla al filo de la medianoche, etc- - o producían conceptos fantásticos como la "fuente de la juventud" o la "piedra filosofal" a fin de justificar sus seudo-operaciones en términos de un objetivo oscuramente adivinado y que finalmente habría de alcanzar la ciencia: la curación por medio de la quimio-terapia y la transmutación de elementos por medio de la química. 9

Este ensayo será, pues, un ejercicio en algo que podríamos llamar alquimia axiológica. Nos enseñará cuál es la diferencia entre el procedimiento "científico" ilegítimo y el legítimo en la teoría del valor; el primero basado en la ideñtificación usual del lenguaje del sentido común con la naturaleza de las cosas, el segundo en la penetración hasta la esencia del tema, que debe-

7 Para un ejemplo de este último procedimiento véàse Robert S. Hartman, "Axiología y Semántica: un Ensayo sobre la Medición del Valor”, Diánoia, 1960, págs. 44-77.

8 Véase La estructura del valor, págs. 102 ss.

9 Véase Henry M. Pachter, Magic into Science: The Story of Paracelsus, Henry Schuman, New York, 1951, para una descripción clara y sencilla de la significación cientifica de la alquimia. 
mos a G. E. Moore.10 Veremos cuán sencilla y elegantemente resuelve la axiología formal problemas de otra suerte sumamente intrincados y realmente irresolubles.

\section{Fớrmulas analiticas y sintéticas: "ejemplificación" y cumplimiento com- prehensivo}

Hall trata de "llegar a" la naturaleza de la realidad del valor "a través de la estructura de las oraciones de valor". 11 Su "programa" consiste en tratar "todas las oraciones predicativas de valor del lenguaje ordinario como oraciones normativas disfrazadas e incompletas". ${ }^{2}$ En otras palabras, dice, "las oraciones predicativas' de valor en el lenguaje ordinario que tienen la forma ' $a$ es bueno', donde $a$ es el nombre de un particular, son incompletas en su componente de valor en una forma que puede ser expresada por el uso de una variable, de modo que ' $a$ es bueno' viene a ser traducida como 'Hay una propiedad $X$ de tal índole, que sería bueno que a ejemplificara a $X$ '. Ahora-bien, esta última oración, a mi juicio y según está formulada, es perfectamente normativa. Esta oración parecería probablemente más aceptable, en cuanto ofrece el sentido cabal 'de ' $a$ es bueno', que, por ejemplo, 'Hay una propiedad $X$ de tal índole, que $a$ debe ejemplificar a $X$ '; pero esto se debe principalmente, creo yo, a que el requerimiento de valor en ella es menos riguroso ('sería bueno que' es una expresión más blanda que 'debe')... Podemos, entonces, preservar e incluso, a mi juicio, aclarar el significado de tales expresiónes 'cotidianas como ' $a$ es bueno' (donde a nombra a un particular) mediante su reemplazo por una conjunción similar a "Hay una propiedad $X$ de tal índole, que a debe ejemplificar a $X$ y a ejemplifica efectivamente a $X$ ". ${ }^{13}$

Veamos primero cómo llega Hall a esta fórmula para "a es bueno", y luego qué significa ésta. Hall llega a esta fórmúla mediante el siguiente argumento en cuatro pasos, en que cada paso sucesivo se supone idéntico en". significación al anterior: (1) " $x$ es bueno", (2) "es bueno que $x . . . "$, (3) "sería bueno que $x . .$. " (4) " $x$ debe..." Veamos cuán legítima es esta secuencia.

(1) Hall comienza su argumento con la perspicacia que es común a todos los axiólogos, de que " $x$ es bueno" significa más de lo que muestra, Lo que no muestra, según Hall, es (i) una propiedad que sea "una especificación del sentido o los sentidos en que se dice que Juan es bueno", ${ }^{14}$ por ej., "benevolente"; y (ii) ninguna oración normativa, pues las oraciones de la forma de "Juan es bueno" son "normativas incompletas". "Por alguna razón,

\footnotetext{
10 Véase La estructura del valor, págs. 39 ss., 231, 273 ss.

11 Hall, op. cit., pp, 162 ss.

12 Op. cit., p. 180.

13 Op. cit., p. 178.

14 op. cit., p. 177 .
} 
ya sea recomendable discreción social o reprobable pereza personal, en tales casos no deseamos formular la oración normativa completa. Omitimos, según el caso, el sujeto o el predicado. Para hacer aparente que tenemos una oración completa, ponemos el todo en una forma aparentemente declarativa con un término de valor como predicado." 15 Hall combina entonces "Juan es bueno" con "Juan es siempre benevolente" de tal manera que, a través de la secuencia de las cuatro proposiciones mencionadas, surge "Juan debe ser benevolente". El primer paso es la identificación de "Juan es bueno" con "Es bueno que Juan siempre sea benevolente". "Entonces no pareceria demasiado inadecuado el pretender que 'Juan es bueno' en esta situación es una forma elíptica de 'Que Juan sea siempre benevolente es bueno' o 'Es bueno que Juan sea siempre benevolente'." 16

Esta identificación, obviamente, es crucial, no sólo para el argumento de Hall sino también para cualquier posición axiológica que él reclame. Pues si " $x$ es bueno" es idéntica a "es bueno que $x$ sea...", entonces, si esto ha de significar algo más que "es bueno que $x$ sea bueno" y, por tanto, "..." representa un atributo distinto de "bueno", la equivalencia significa que se incurre en la falacia naturalista. Pues la bondad de $x$ se identificaría con la bondad del hecho de que $x$ tiene alguna propiedad distinta de lo bueno, es decir, benevolencia o amabilidad; y esta identificación es un aspecto de la falacia en cúestión. No es ciertamente ninguna fruslería, para una teoría del valor, proponer un "programa" de este tipo; y el hacerlo sin ningún examen, en el meollo mismo del argumento, parece ser menos que "analítico", excepto en nuestro propio sentido de la palabra, que significa falta de penetración sintética. Hall pasa por alto todas las cuestiones fundamentales relacionadas con esta identificación, diciendo que "no parecería demasiado inadecuada". A la luz de la axiología formal sí lo pareceria, pues no sólo hay una clara diferencia lógica ${ }^{17}$ entre " $x$ es bueno" $y$ "es bueno que $x$ sea...", diferencia que resulta obvia incluso al examen del sentido "común; también existe la profunda y clara diferencia áxiológica ya mencionada. La identificación de las dos expresiones significa que la bondad de $x$ puede ser identificada con la bondad de que $x$ tiene cualquier propiedad: " $x$ es bueno" puede significar "es bueno que $x$ sea $\varphi$ ", donde $\varphi$ representa cualquier propiedad. De tal suerte, " $x$ es bueno" puede significar "es bueno que $x$ sea benevolente", pero también puede significar "es bueno que $x$ rebane pescuezos", "es bueno que $x$ vomite", "es bueno que $x$ sea una raí cuadrada", etc., etc. Así, la identificación no sólo incurre en la falacia naturalista; ni siquiera fija un límite a la propiedad distinta de "bueno" que $x$ ha de tener para ser bueno. Este primer paso, entonces, es tan vago que en

15 Ibid.

16 Op. cit., pp. 177 ss.

17 Véase La estructura del valor, pág. 238. 
realidád carece de significación. El análisis de Hall en este punto crucial es mucho más oscuro que el de Moore, quien al menos hizo que "bueno" dependiera de las propiedades naturales de la cosa que es buena. Y es, desde luego, mucho más vago que nuestra propia teoría que define la de Moore y determina en detalle la propiedad $\varphi$ que $x$ debe poseer a fin de ser bueno, a saber, las propiedades de la clase de la cual se dice es un buen miembro. Así, pues, es difícil escapar a la conclusión de que la primera etapa del argumento de Hall —decir que " $x$ es bueno" es equivalente a "es bueno que $\dot{x}$ sea..."- es lógicamente falsa y axiológicamente ilegitima. Realmente parece carecer de significación.

(2) El segundo paso reúne estos errores. Hall identifica ahora "es bueno que $x$ sea..." con "sería bueno que $x$ fuera..."; y hace tal cosa por la razón peculiar de que muestra "la afirmatividad del valor" como algo diferente de la afirmatividad del hecho".18 Pues la oración "Es bueno que Juan siempre sea benevolente", "aparentemente afirma un hecho además de un valor, a saber, que Juan siempre es benevolente. Yo no intento refutar esto. Bien puede ser que toda oración con predicado de valor similar a 'Juan es bueno' (al suprimir su verdadero predicado) sea en parte una afirmación factual elíptica. Pero, de ser así, podemos poner este elemento factual a un - lado, pues claramente no lo es todo. La oración con predicado de valor es también una oración de valor, y es ésta la que por el momentó estamos tratando de analizar. Pongamos este componente en la forma de subjuntivo, no proponiéndonos con ello indicar ninguna contrariedad-al-hecho, sino únicamente la afirmatividad del valor como algo diferente de la afirmatividad del hecho. En la situación considerada anteriormente, 'Juan es bueno' es, en relación con su componente de valor, una forma elíptica de 'Sería bueno que Juan siempre fuera benevolente" ".19

Antes que nada, no hay razón para que "sería bueno que $x$ fuera..." deba ser una afirmación de valor, excepto sobre la base del supuesto de Hall de que (a) un valor es normativo, y (b) "sería bueno, etc." es una expresión normativa. Pero, sobre esta base, este paso es superfluo puesto que da por admitido el punto en discusión; y, dado que no hay otra base para esta identificación, ella es arbitraria y errónea como la primera. Una vez más, existe una diferencia lógica fundamental entre "Es bueno que Juan sea benevolen$t^{\prime \prime}$ y "Sería bueno que Juan fuera benevolente", diferencia que es obvia al examen del sentido común y que Hall introduce mediante una especie de juego de manos, explotando la vaga similitud que existe entre "diferente del hecho" y "contrario al hecho". Hay una' fundamental significación axiológica en esta sustitución del indicativo por el subjuntivo; péro no es la que Hall tiene en mente. Hall introduce la "forma valorativa del condicional

18 op. cit., p. 178.

19 Ibid. 
contrario-aI-hecho" 20 a fin de explicar un fenómeno que lo desconcierta en grado sumo y que podríamos llamar la naturaleza de "gato de Cheshire" del hecho y del valor: que puede haber valor sin hecho, como puede haber mueca sin gato. "Recordemos qué es lo que se necesita. Se sostiene que el valor es una propiedad de los hechos. Sin embargo, se reconoce que en cierto sentido es independiente de los hechos; puede existir cuando el hecho apropiado no exista y puede ser afirmado sin la afirmación del hecho correlativo. Para mitigar esta paradoja se recurre a los condicionales contrarios-al-hecho, a oraciones de la forma de 'Si a fuera $A$ sería bueno' o 'Si el caso fuera que $a$ es $A$, ése [estado de cosas] sería bueno'. Aquí, 'bueno' parece operar como un predicado cuyo sujeto es una referencia a un estado de cosas que no existe".21 Hall es llevado a esta construcción lewis-carrolliana por su concepción seudo-ontológica del valor. El valor "es" y el hecho "es", pero las maneras en que "son" constituyen un misterio; de algún modo están unidos y de algún modo no lo están, y mediante la introducción de la "forma valorativa del condicional contrario-al-hecho", Hall de algún modo trata de "mitigar" la "paradoja" en un intento de tener su pastel factual con o sin su relleno de fruta valorativa, y viceversa, el relleno con o sin el pastel. O, para usar el contexto de Alicia en el Pais de las Marvillas, de ir en ambas direcciones al mismo tiempo o en ninguna, puesto que ambos, el hecho $y$ el valor, son desconocidos. ${ }^{22}$

En nuestro análisis, el problema de si el valor puede aparecer sin el hecho o el hecho sin el valor, es tan significativo o tan carente de significación como el problema de si lo convexo puede aparecer sin lo cóncavo o lo cóncavo sin lo convexo, o, para seguir dentro del contexto de Alicia..., de si el gato de Cheshire está loco porque gruñe cuando está contento y menea la cola cuando está enojado, o si el perro está loco porque gruñe cuando está enojado y menea la cola cuando está contento. En otras palabras, el problema carece de significación, pues presupone la determinación previa de la manera en que el hecho y el valor "son". Para nosotros, no "son" en absoluto: son dos en una infinidad de aspectos en los que cualquier dato puede aparecer (otro de tales aspectos puede ser, por ejemplo, el musical). ${ }^{23}$

\footnotetext{
20 op. cit., p. 59.

2l Ibid.

22 "¿Podriais decirme, por favor, qué camino debo tomar para irme de aquif?

'Eso depende, en buena medida, del lugar adonde queráis ir', dijo el Gato.

'No me importa mucho...', dijo Alicia.

'Entonces nỏ importa qué camino toméis', dijo el Gato.

'...con tal de llegar a alguna parte', añadió Alicia a guisa de explicación.

'Oh, eso sin duda lo lograréis', dijo el Gato, 'con tal de que caminéis lo suficiente.."

23 La totalidad de esos aspectos es el valor (La estructura del valor, págs. 265 sigs.). El hecho es una propiedad específica del valor descompuesta en propiedades primarias de valor, que reciben el nombre de propiedades "descriptivas". A la inversa, entonces, el valor es la cuantificación de las propiedades descriptivas. Es, entonces, posible para el valor aparecer sin el hecho, como para el hecho aparccer sin el valor. Si una propiedad de valor
} 
Asi, pues, la sustitución del indicativo por el subjuntivo que hace Hall, no tiene, para nosotros, la significación axiológica que tiene para él. Pero sí tiene otra significación que hace que esta sustitución sea no ya impertinente - como en el caso antes mencionado-, sino ilegítima. La sustitución se hace a fin de mostrar la diferencia entre la "afirmatividad del valor" y -la "afirmatividad del hecho". Se presupone que "Juan es benevolente" es "afirmatividad del hecho". Una vez más, esto parèce obviamente erróneo, pues una persona que es "benevolente" es claramente una persona que posee un valor. La vaguedad del análisis de Hall y su identificación de lo valorativo con lo normativo lo hace pasar por alto el obvio carácter valoral de otros predicados de valor distintos de "bueno", y no le proporciona criterio alguno para diferenciar entre ellos, aun si los reconociera como predicados de valor. Así, pues, aunque este segundo paso en el argumento presupone un criterio para distinguir entre los predicados de valor y los predicados de hecho, la doctrina de Hall carece de tal criterio. ${ }^{24}$ Más aún, la doctrina vicia la fórmula final de Hall, pues la "propiedad" que Juan debe ejemplificar y ejemplifica a fin de ser bueno, puede entonces ser una propiedad de valor lo mismo que una propiedad de hecho; y en el ejemplo de la benevolencia que ofrece Hall, realmente es una propiedad de valor, lo cual destruye toda la distinción sobre la que Hall basa su análisis. Pues, en lugar de "especificar" la propiedad de valor "bueno" mediante una propiedad de hecho, él la "especifica" mediante una propiedad, "benevolente", que tiene las mismas deficiencias, en el análisis de Hall, que el propio "bueno", a saber, que es es la cuantificación de las propiedades descriptivas de una cosa, y la cosa y sus propiedades descriptivas son el hecho, entonces el valor seria por sí mismo la cuantificación de las propiedades descriptivas $\sin l a \cos a$. El lenguaje tiene un medio ingenioso de expresar ese mero valor: la metáfora. Una metáfora es un conjunto de propiedades descriptivas sin su referente $y$, por tanto, es aplicable a cualquier cosa. Es, en otras palabras, pura comprehensión. Un durazno metafórico es el conjunto de las propiedades del durazno, o la comprehensión del durazno, aplicable a cualquier cosa. Un durazno de muchacha (la frase en inglés es "a peach of a girl", que en español se diría "una monada de muchacha" o "un encanto de chica"), un durazno de automóvil, un durazno de perro, vienen a ser aplicaciones de tal tipo. Si una muchacha, un automóvil, un perro son descriptivamente miembros de sus respectivas clases $C$, con sus respectivos conjuntos de propiedades de clase, $\Phi$, y un durazno es un miembro de $s u$ clase, $D$, con su conjunto de propiedades de clase, $\psi$, cntonces, en un durazno de muchacha, la "muchachidad" $\Phi$ de alguna muchacha $x$ ha sido imbuida de "duraznidad", $\psi$, lo cual quiere decir quc la "muchachidad" de $x$ es "de durazno", o que $x$ es un durazno de muchacha. Esto podría significarse con $\psi(\Phi x)$. Puesto que, teóricamente, cualquier comprehensión puede servir como metáfora, cualquier nombre, como pura comprehensión, puede servir como propiedad de valor para cualquier combinación' de comprehensión y cxtensión, es decir, para cualquier otro nombre que sea al mismo tiempo significado y ejemplificado. Esto quiere decir que el lenguaje de la metáfora es (1) el lenguaje de la pura comprehensión sin referencia extensiva, (2) que si el lenguaje descriptivo es denumerablemente infinito de elementos $\left(x_{0}\right)$, entonces el lenguaje metafórico es non-denumerablemente infinito de elementos $\left(x_{1}\right)$, puestó que cada uno de sus elementos denumerablemente infinitos tiene aplicaciones denumerablemente infinitas y $2 x_{0}=x_{1}$.

$24 o_{p}$. cit., p. 184, nota al calce. 
un predicado de valor. De tal suerte, Hall explica ignotum per ignotius. Este segundo paso, pues, no sólo incorpora el error del primero, sino que es en sí mismo lógicamente erróneo y axiológicamente ilegítimo.

(3) El tercer paso es la identificación 'de "sería bueno que" con "debe". Una vez más, ni se explica ni se analiza, excepto al decir que " "sería bueno que...' es una expresión más blanda que 'debe" " y que es "menos rigurosa". Pero el significado lógico de "más blanda" y "menos rigurosa" no se da en ninguna parte, aunque el "programa" se basa supuestamente en la estructura lógica de las oraciones de valor; ni podría darse, pues éstos no son términos lógicos. Son expresiones típicamente analíticas, en nuestro sentido del vocablo, que quiere decir sintética o lógicamente carentes de significación. Axiológicamente, la identificación es falsa, pues "debe" es equivalente a "es mejor que...". ${ }^{25}$ Si Hall quiere establecer que es equivalente a "sería bueno que...", tendría que demostrar esto lógicamente y dentro de un patrón coherente y explícito. Según está formulado, el tercer paso sólo puede ser considerado lógicamente carente de significación y axiológicamente falso.

Toda la secuencia, entonces, es de inconsecuencias. Se basa en aparentes identidades de expresiones de "bueno", sin análisis del contexto lógico en que aparece "bueno". Agrupa significados enteramente diferentes, tales como "es bueno", "es bueno que", "sería bueno que", ya sea sin examinar, o examinando de una manera extravagante, las relaciones lógicas y axiológicas entre esas expresiones. Es, pues, el ejemplo típico de un argumento analítico en contraste con uno sintético, de un argumento del "sentido común" en oposición a uno científico. Resulta difícil ver en qué sentido, metodológica y lógicamente, este argumento es diferente del de Francesco Sizzi contra las lunas galileanas de Júpiter. ${ }^{26}$ Lo que para Hall es la palabra del sentido común "bueno", para Sizzi era la palabra del sentido común "siete". El argumento de Sizzi se basa en aparentes identidades de expresiones de "siete" sin análisis de los contextos en que aparece "siete". Agrupa significados enteramente diferentes, tales como "siete ventanas en la cabeza", "siete metales", "siete dias de la semana", "siete planetas", sin examinar, o examinando de una manera extravagante, la relación lógica y cientifica entre esas expresiones. Es, así, un ejemplo típico de un argumento analítico en contraste con uno sintético, de un argumento del "sentido común" en oposición a uno científico. Sizzi utilizó el número "siete" analíticamente y no como Galileo, sintéticamente; y Hall utiliza el término axiológico "bueno" analíticamente y no como se utiliza en la axiologia formal, sintéticamente. De tal suerte, su argumento es un ejemplo de lo que llamamos alquimia (o astrología) axiológica.

Añadiendo a esta utilización no crítica de las expresiones de "bueno",

25 Véase La estructura del valor, págs. 239 ss.

26 Op. cit., pág. 65. 
en el segundo paso, la identificación que hace Hall de los términos de valor con los términos de hecho, resulta difícil ver por qué se ha emprendido toda la argumentación y por qué Hall no se limitó simplemente a proponer -más bien que a deducir o tratar de justificar_ " $a$ es bueno" como significativo de "Existe una propiedad $X$ de tal índole; que $a$ debe ejemplificar a $X$ y a ejemplifica efectivamente a $X$ ". Como una deducción o argumento que conducé de " $a$ es bueno" a esta fórmula, los pasos del argumento de Hall no sólo son superfluos - pues se basan en la premisa que se supone surge como una conclusión, de que lo valorativo es lo normativo-, sino que además son nocivos a su tesis, pues sus propios errores iluminan la ilegitimidad de esta premisa.

Los tres pasos son defectuosos por lo que respecta a la distinción entre hecho y valor. La primera afirmación, en particular, " $x$ es bueno", es una oración de valor genuina, y es elíptica no porque omite una oración normativa, sino porque oculta una serie de proposiciones puramente lógicas: el patrón de valor que examinamos en otro lugar. ${ }^{27}$ El argumento de Hall no es adecuado para justificar la suposición de que esta expresión es normátiva, pues su normatividad surge únicamente a través de los pasos defectuosos en cuestión. Esto prueba, a contrario, que las oraciones declarativas pueden ser tan valorativas como las normativas, y las normativas tan factuales como las cleclarativas. "Juan es bueno" es una oración de valor con una cópula de hecho, y "Juan debe atar los cordones de sus zapatos" es una oración de hecho, con una cópula de valor - la primera una proposición lógica mixta, la segunda una proposición axiológica mixta, según nuestra terminología-28 A menos que se haga la cuádruple división de proposiciones de valor que propusimos —entrê proposiciones lógicas puras, lógicas mixtas, axiológicas mixtas y axiológicas puras - resulta difícil ver cómo puede ponerse orden en la relación entre las oraciones de hecho y las de valor. La simple identificación de oraciones normativas de "debe" con el valor, y de oraciones de "es" con el hecho, y el intento de convertir las oraciones de "es" con predicados de válor en oraciones normativas, conduce a la confusión que antes hemos expuesto.

En términos de la axiología formal, las oraciones de hecho son lógicas puras _ " $x$ es $C$ " - y las oraciones de valor son axiológicas puras _ " $x$ debe ser bueno"-. En lugar intermedio están las lógicas mixtas (lógico-axiológicas) - " $x$ es bueno"- y las axiológicas mixtas (axiológico-lógicas) - " $x$ debe ser C"- Si queremos utilizar la terminología de hecho-valor, podríamos decir que las primeras son puramente factuales, las segundas puramente valorativas, las terceras factuales-valorativas, y las cuartas valorativas-factuales. Pero éstos son términos típicamente vagos y materiales que sig-

27 Op. cit., págs. 229 ss.

28 Op. cit., págs. 243 ss. 
nifican poco. ${ }^{29}$ En el "análisis filosófico" de Hall, sólo las que llamamos proposiciones axiológicas - aquellas con cópula "debe" - son valorativas; y Hall tiene que retorcer el lenguaje a fin de (a) no excluir las proposiciones lógicas mixtas y (b) de incluir las proposiciones axiológicas mixtas. El resultado es (a) la secuencia que expusimos, y (b) los absurdos tales como considerar imperativos misceláneos - "iCorra!", "¡Fume!”, “ ‘Límpiese los dientes!" y las diversas formas de Paco usa o no usa, tiene que usar o no usar, debe usar o no debe usar los chanclos de goma- como pertinentes a la naturaleza de la valoración. El análisis de estas y otras formas de la "lógica imperativa" son ejemplos de lo que queremos decir cuando hablamos de alquimia axiológica. ${ }^{30}$. Las expresiones lingüísticas son valorativamente pertinentes no tan sólo por su estructura, sino por su estructura como expresión de un fenómeno de valor materialmente discernido. 'Carente de tal penetración fenomenal, la mera estructura es capaz de conducirnos a extravíos. Antes de examinar esto en detalle, y entrar así en la esencia de este tipo de enfoque "normativo" - cuyos errores expuestos hasta ahora son sólo manifestaciones, debemos examinar el propio "programa" de Hall y ver, independientemente de su "deducción", qué dice y cómo se relaciona con la axiología formal.

Tomemos, entonces, la fórmula de Hall para "bueno" en su valor aparente: " $a$ es bueno" significa "Hay una propiedad $X$ de tal índole, que $a$ debe ejemplificar a $X$ y a ejemplifica efectivamente a $X$ ". Esto, tal y como está formulado, puede significar cualquier cosa; vrg. "Juan es bueno" significa que "hay una propiedad 'patizambo' tal, que Juan debe ejemplificar a 'patizambo' y 'Juan en realidad ejemplifica a 'patizambo'". Esta fórmula, como tal, es pues demasiado lata $y$, por tanto, inútil. Pero puede ser especificada en un sentido axiológicamente válido. Antes que nada, debe ser formulada de modo que no incurra en la falacia naturalista. Así, en lugar de definir " $a$ es bueno", debe definir " $a$ es ún buen $A$ ". La propiedad $X$, en lugar de ser cualquier propiedad, es entonces la propiedad de clase de $a$, es decir $A$, y "ejemplificación" es condición de miembro de clase. "Debe", que es un término indefinido, debe ser reemplazado por "es". El resultado es el axioma de la axiología formal, en su forma originalmente propuesta, ${ }^{31}$ a saber: " ' $x$ es un buen $A$ ' significa que ' $x$ es un miembro de $A$ y tiene todos los atributos de $A$ "'.32 El axioma de la axiología formal es, entonces, una especificación del vago enunciado de $\mathrm{Hall}$; es la formulación de su contenido analítico en forma sintética: en términos de relaciones estrictamente

29 op. cit., pág. sog, nota al calce $13 \mathrm{a}$.

30 Véase Hall, op. cit., pp. 125 ss.

31 En la relación del autor a la Cuadragésimonovena Reunión Anual de 'la División Occidental de la Asociación Filosófica Norteamericana, Evanston, Ill., 3 de mayo de 1951 .

32 "A Logical Definition of Value", en Journal of Philosophy, XLVIII, 413-120 (21 dejunio de 1951). 
lógicas. Y la fórmula de Hall, en esta especificación lógica, es la forma "debe" de nuestro axioma: " ' $x$ es un buen $A$ ' significa que ' $x$ debe ser un miembro de $A$ y $x$ es un miembro de $A^{\prime \prime} .{ }^{33}$ En esta especificación, lo que Hall define no es " $x$ es bueno", sino " $x$ es un buen $A$ "; y en realidad no hay ninguna expresión " $x$ es bueno" que no signifique, para Hall, "ejemplificación" de alguna propiedad, sólo que, en su formulación, esto no significa nada lógicamente. En nuestra especificación sí, a saber, lo que usualmente significa en la lógica: condición de miembro de clase. Así, pues, "Sócrates es bueno" no significa ya, como para Hall, que "Sócrates debe ser y es algo" sino que "Sócrates es un buen..." o sea "Sócrates es un miembro de $\boldsymbol{A}$ y tiene todas las propiedades de $A "$. Como se ve, la fórmula de Hall está, en cierto respecto, muy cerca de la nuestra. Se acerca a la formulación lógica tanto como puede acercarse cualquier determinación analítica de "bueno" y "debe". Todo lo que él habría necesitado para alcanzar realmente la formulación lógica, hubiese sido tomar en serio -lógica y no metafóricamente, sintética y no analíticamente- su término "ejemplificación", y sin dar por admitido lo que está en discusión, es decir, sin presumir que la propiedad ejemplificada es una propiedad de valor ${ }^{34}$

Desde èl lado de esta propiedad, la fórmula de Hall para " $A$ es bueno" es "para cualquier particular $x$, si $x$ ejemplifica a $A$, entonces sería bueno que $x$ ejemplifique a $A^{\prime}$ o (dicho con más crudeza) 'Para cualquier $x$, si $x$ ejemplifica a $A$, entonces $x$ debe ejemplificar a $A$ "'. No existe razón alguna por la que esto no deba interpretarse como que "Ser hombre es bueno" sig. nifique "Si Sócrates es un hombre, entonces Sócrates debe ser bueno". Esto sería notablemente similar a nuestra definición de "débe" y el teorema de que $x$ debe ser bueno es siempre verdadero; puesto que $x$ es un $A$, es mejor para $x$ cumplir las propiedades de $A$ que no cumplirlas. ${ }^{35}$ Desgraciadamente, éste no parece ser el significado de Hall. Más bien, "A" para él parece representar un "valor" universal, tal como "placer". Pero la fórmula no expresa esto, y así, a despecho de su creador, se aproxima a la nuestra.

Entre la fórmula de Hall para "bueno" y "debe" y la nuestra existe una diferencia mínima. Sin embargo, esta diferencia mínima cubre el abismo entre el pensamiento analítico y el sintético. La teoría de Hall se basa en el vago e indefinido concepto analítico "ejemplificación", en tanto que la nuestra se basa en el concepto sintético exactamente definido de cumplimiento comprehensional. La razón del poder de la segunda y la impotencia de la primera, como fundamento axiológico, consiste en que la segunda tiene y la primera carece de alcance tanto sistemático como empírico. La axiología formal tiene alcance sistemático porque la comprehensión es un elemento

\footnotetext{
33 Ĺste es "debe" analitico. Véase La estructura del valor, págs. $248 \mathrm{ss}$.

34 What 1 s Value? p. 179 .

30 La estructura del valor, pág. 24 o.
} 
bien definido en un sistema: el de la lógica; y tiene alcance empírico porque su axioma se basa en la profunda penetración en la naturaleza del fenómeno de valor mismo, en la comprensión profunda mooreana de la naturaleza de la bondad. Lá fórmula de Hall, en cambio, carece de alcance sistemático porque consiste en conceptos vagos, tales como "ejemplificación": conceptos analíticos que, como se ha expresado, "pueden ser definidos fácilmente en cualquier número", pero son "inútiles para fines sistemáticos". ${ }^{36}$ Así, al carecer de alcance sistemático, carece también de alcance empírico.

\section{La simbolización de "Debe"}

Si esto fuera todo, la explicación de Hall no sería esencialmente diferente de otras explicaciones analíticas de la bondad, tales como las que se hallan usualmente en la axiología filosófica o material. Pero Hall va un paso más lejos, y es esto lo que hace que su procedimiento sea tan serio. No bastándole utilizar su fórmula como un mapa para la selva, pretende también utilizarla para la construcción de instrumentos cartográficos. Pretende construir un simbolismo sobre ella. En otras palabras, utiliza conceptos analíticos para producir formulaciones sintéticas. Una cosa es tratar de entender la realidad fenomenal con vagos conceptos filosóficos, y otra poner esos conceptos en forma simbólica. Si los conceptos vagos son incapaces de constituir un mapa de la tierra, scómo podrán constituir un mapa de las estrellas?

Puesto que la naturaleza del valor, dice Hall, "brilla a través de" la estructura de las oraciones normativas como el de los hechos brilla a través de la de las oraciones declarativas, todo lo que se necesita para elaborar un simbolismo para las oraciones de valor es reemplazar el paréntesis en la expresión " $A(a)$ ", que representa " $a$ ejemplifica a $A$ ", por corchetes "A $\{a\}$ " y tenemos una notación para oraciones de valor, " $a$ debe ejemplificar a $A$ ".37 Esta nueva notación que, según Häl, "es mucho mejor en algunos respectos y mucho peor en otros que otros modelos", 38 ha sido enmendada en escritos subsecuentes, especialmente como resultado de una discusión con E. M. Adams; y en dos respectos, cuyo fin es mostrar "la fundamental incrustación semántica de las declarativas en las normativas", a saber las formas " $B(a)\}$ $A(a)$ ", que ha de leerse "si $a$ ejemplifica a $B$, entonces debe ser el caso que ejemplifique a $A$ ",, y las formas "( ( $x$ ) $A\{x\}$ " y " $\{\mathrm{x}\} \mathrm{A}[\mathrm{x}]$ ", que han de leerse respectivamente "algo debe ejemplificar a $A$ " y "debe haber algo para

36 C. G. Hempel, Fundamentals of Concept Formation in the Empirical Sciences, Chicago, 1952, pág. 46. Cf. La estructura del valor, págs. 11255.

37 What Is Value? pp. 152, 183 .

38 "Existential Normatives", en Journal of Philosophy, LV, p. 75 (16 de enero de 1958).

39 E. M. Adams, "Further Words on 'Ought", en Philosophical Studies, VII, p. 76 (oc. tubre de 1956). Véanse también E. M. Adams, "The Nature of Ought", en Philosophical Studies, VII, 36-42 (abril de 1956), y "Ought Again", en Philosophical Studies, VIII, 86-89 (diciembre de 1957). 
ejemplificar a $A$ ". Estas últimas son formas inventadas por Adams y usadas para argumentar contra el paralelismo de Hall entre hecho y valor, paralelismo que es la bàse misma del argumento de Hall, y que Hall acepta. ${ }^{40}$.

Precisamente en relación con este último simbolismo surge el problema práctico con el que ahora someteremos a prueba tanto la teoría de Hall como la nuestra.

El problema es el de la expresión notacional de las dos proposiciones: "Hay un $a$ que debe ejemplificar a $A$ " y "Debe haber un $a$ que ejemplifique a $A$ ". Deber haber, dice Adams," no es deber ejemplificar. "Debe haber algo para ejemplificar a $A$ ' es bien diferente de 'algo debe ejemplificar a $A$ '. Esta última puede ser simbolizada por '( $(\exists x) A\{x\}$ ', combinando una notación familiar con la notación de Hall para las normativas, y eso nos da sólo una forma generalizada de $A\{a\}$, sin ninguna significación particular para nuestro propósito. Pero la primera, 'debe haber algo para ejemplificar a $A$ ', es un asunto diferente. Apoyándose una vez más en notaciones convencionales, la sugestión de Hall para las normativas, e improvisando hasta cierto punto, esto podría ser simbolizado por ' $\{\mathrm{A} x\} A[x]$ ' y leído "debe haber algo que ejemplificaría a $A^{\prime}$. Éste parece ser un tipo básico de normativa. No sólo es irreducible ni a ' $A\{a\}$ ' ni a '( $\exists x) A\{x\}$ ', sino que 'no es implicado por ninguna de ellas ni las implica. 'Algo debe ejemplificar a $A$ ' no implica 'debe haber algo que ejemplificaria a $A^{\prime}$ ', pues si el algo que debe ejemplificar a $A$ no existiera, podría no ser el caso que $A$ deba ser ejemplificado en absoluto. Y tampoco 'debe haber algo que ejemplificaría a $A$ ' implica' 'hay algo que debe ejemplificar a $A^{\prime}$. Podría ser debe haber un hombre que se casaria con Juana y sin embargo no hay un hombre que se deba casar con Juana".

Así, Adams descubre un nuevo tipo de normativa no incluido por Hall. "El deber-ser o el deber-existir de un particular parece ser un tipo básico de normativo que nosotros si conseguimos enunciar en lenguaje ordinario, pero que no puede enunciarse en el lenguaje ideal que sugiere Hall con ' $A\{a\}$ ' como la forma normativa standard. El hecho de que no reconozca esto parece influir significativamente sus conclusiones acerca de la naturaleza de debe y, puesto que las identifica a las dos, acerca de la naturaleza del valor. No existe la misma dificultad acerca del hecho. Mientras lo que se dice en la 'forma de ' $\{\mathrm{a} x\} A[x]$ ', no puede decirse en la forma de ' $A\{a\}$ ' no veo dificultad en decir cuálquier cosa que sea decible en la forma ' ( $(x) A(x)$ ' en la forma de ' $A(a)$ '. Así, un lenguaje ideal podría concebiblemente llevarse bien con las formas de hecho de $A(a)$ y $A(a, b)$, pero no con las formas de debe de $A\{a\}$ y ' $A\{a, b\}$. Esto arguye en contra de la teoría [de Hall] del op. cit.

40 E. M. Adams, "Hall's Analysis of 'Ought", E. W. Hall, "Existential Normatives", 41 Journal of Philosophy, LV, p: 74 (16 de enero de 1958).. 
paralelismo entre hecho y valor y su alegación de que todo valor, en cierto sentido, contiene un hecho correspondiente, y especialmente en contra de la alegación de que la naturaleza del valor es mostrada por la forma ' $A\{a\}$ ' o 'A $\{a, b\} . " 42$

Esta conclusión, desde luego, deja sin base a toda la teoría de Hall. Éste, lejos de molestarse, no sólo concede que Adams tiene razón, sino que ofrece la otra mejilla, demostrando que el simbolismo ni siquiera representa adecuadamente la forma que Adams ácepta, es decir, "Hay un a que debe...". "La forma en que deberíamos manipular los operadores existenciales en una lógica normativa y permanecer fieles (en general) al lenguaje ordinario, es un acertijo aunque no tan desconcertante como para propugnar el completo abandono de la clarificación mediànte lenguajes modelos." 43 Hall trata entonces varias posibilidades de explicar simbólicamente la distinción de Adams, pero sin éxito.

Tenemos aquí, entonces, un problema definido: explicar dos expresiones axiológicas verbales; tenemos un simbolismo propuesto; y tenemos el fracaso de un simbolismo para explicar las expresiones. También en la axiología formal tenemos un simbolismo. Así, pues, tenemos aquí un perfecto caso de prueba para la comparación de dos simbolismos axiológicos. Veamos primero cuán sencilla y elegantemente resuelve el problema la notación de la axiología formal, y examinemos lucgo la razón por la cual la de Hall no lo resuelve. En nuestra notación, como lo demuestra una ojeada al cuadro, en la pág. 252, de La estructura del valor, "Debe haber un hombre que se casara con Juana"

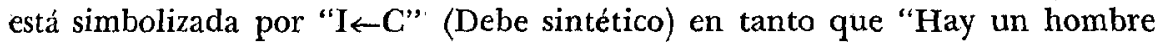
que debe casarse con Juana" es " $\mathrm{I} \rightarrow \mathrm{C}$ " (Debe analítico). Como se ve en el cuadro, la primera presupone el juicio lógico subyacente: "No hay un hombre que se case con Juana", E-C, y la segunda: "Hay un hombre que se casa con Juana", I-C. Se ve también que hay un segundo significado para "Debe haber un hombre que se case con Juana", basado en el juicio lógico subyacente $\mathrm{O}-\mathrm{C}$, "Hay un hombre que no se casa con Juana". Esta última posibilidad ha escapado tanto a Hall como a Adams.

La razón por la que la notación de Hall no es capaz de resolver el problema es que él no ha derivado el simbolismo de las cualidades primarias del fenómeno, sino que meramente ha adaptado un simbolismo a cualidades secundarias del fenómeno. En otras palabras, no ha penetrado hasta la naturaleza esencial del fenómeno, hasta su noción axiomática, para derivar de ella una notación, sino que ha inventado una "notación arbitraria" 44 en términos de la cual entender el fenómeno. Esto significa, desde luego, que para cada nuevo caso él -o alguno de sus colegas_. tendrá que desarrollar

42 Op. cit., p. 75 .

43 Ibid.

44 What Is Value?, p. 183 , nota al calce. 
un nuevo simbolismo; pues no hay un axioma único basado en la naturaleza del propio fenómeno y del cual se derive el simbolismo.

La penetración en el simbolismo habría mostrado, en el presente caso, que la distinción establecida por Adams no es tanto una cuestión del operador existencial como del propio "debe". La naturaleza del "debe", y no la del operador existencial, es lo que distingue a las dos proposiciones. El "debe" en la primera proposición es axiológicamente sintético; en la segunda es axiológicamente analítiço. La diferencia entre los dos fue definida por la modalidad de los juicios lógicos subyacentes de la proposición axiológica de "debe". Las proposiciones sintéticas de "debe" presuponen que lo que debe ser no es el cáso: la modalidad del juicio lógico subyacente es negativa; las proposiciones analíticas. de "debe", en cambio, presuponen que lo que debe ser es el caso: la modalidad del juicio lógico subyacente es afirmativa.4r

$\mathrm{El}$ caso presente es un ejemplo perfecto de tales proposiciones de "debe" y confirma la validez de nuestra interpretación. Ambas proposiciones tienen la forma "Alguien debe casarse con Juana". Lsta es una proposición lógica " $I$ " con una cópula axiológica $y$ un predicado no-axiológico, una proposición axiológica mixta. ${ }^{40}$ Por consiguiente la forma general es "I flecha C", en donde la naturaleza de la flecha está determinada por la analiticidad, la sinteticidad o la hipoteticidad de "debe". En el primer caso, "Debe haber un hombre que se casará con Juana", el propio Hall nos da la formulación de la axiologia formal: "Debe haber un hombre [pero yo me sospecho que no hay ninguno] que se case con Juana'.". 47 La forma notacional es " $\mathrm{I} \leftarrow \mathrm{C}$ ", la proposición tiene el valor de verdad axiologica de la Indeterminación, ${ }^{48}$ y el juicio subyacente es E-C. En el segundo caso, la formulación de Hall es " 'Hay un hombre [itú sabes cuáll] que debe casarse con Juana'", que nuevamente es la misma que nuestra propia formuláción "Debe haber un hombre que se case con Juana [iy sí lo hay!]" o "Un hombre [itú sabes quićn!] debe casarse con Juana". Así, pues, esta proposición axiológica confirma lo que se presume que es el caso, su forma es $I \rightarrow C$, su valor de verdad axiológico es là Verdad, y el juicio subyacente es I-C. Está, por último, el ćaso que tanto Hall como Adams pasan por alto, el cual, en la formulación de Hall, sería "Debe haber un hombre [itú sabes quién!] que se case con Júana [pero sospecho que no lo hará]", la forma $\mathbf{I} \leftarrow \mathbf{C}$ con el juicio subyacente O-C más bien que E-C. Esta última forma muestra de manera especialmente clara que la carga del problema no descansa tanto en el cuantificador existencial como en el "debe" mismo; no puede ser formulada por ninguna de las, formas discutidas por Hall y Adams. ${ }^{49}$ El cuantificador exis-

4ó Véase La estriuctura del yalor, págs. 246 ss.

46 Op. cit., pág. 243.

47 "Existential Normatives", op. cit., p. 75 .

48 R. S. Hartman, "Value Propositions", The Language of Value, Ray Lepley, N. Y., 1957, pp. 229 ss. 49 Ibid. 
tencial, como vemos en las tres formas, no pertenece tanto a la proposición de "debe" como a los juicios subyacentes. Ésta es, pues, nuestra solución del "acertijo" de Hall: "cómo deberemos manejar los operadores existenciales en una lógica normativa y permanecer fieles al lenguaje ordinario".50

La razón del poder diferente de las notaciones, la "arbitraria" de Hall y la sistemática de la axiología formal, ${ }^{51}$ es que la segunda ha sido desarrollada sobre la base de una noción axiomática del fenómeno y la priméra no. La axiologia formal intenta ser una teoría consistente, deducida de un axioma que está definido con precisión, en detalle lógico, y sobre la base del propio fenómeno. Nuestros símblos " $\mathrm{I} \leftarrow \mathrm{C}$ " $e$ " $\mathrm{I} \rightarrow \mathrm{C}$ " no son arbitrarios, sino que representan relaciones precisamente definidas dentro de un sistema sintético. En este sistema, basado en la definición de "bueno" más bien que en la de "debe", el propio "debe" aparece como una relación precisa, la relación entre èl no-cumplimiento y el cumplimiento de un concepto, y los diversos modos de deber están exactamente definidos. Ningunas otras consideraciones que no sean las definidas entran en el problema. En particular, es claro en nuestra interpretación que la discusión de Hall de la naturaleza del cuantificador existencial es impertinente al problema en tanto esté basada en símbolos arbitrarios y no en comprensión fenomenal. Pues tales símbolos nunca pueden expresar la diferencia modal entre proposición y juicio que caracteriza esencialmente a toda proposición de "debe". Así, pues, la conjetura.de Adams al efecto-de que hay una diferencia entre el deber-ser y el deber-ejemplificar, si bien es correcta, no tiene nada que ver con el presente problema, o sea el de expresar la diferencia entre los hombres que pudieran casarse con Juana. La conjetura pertenece a un círculo enteramente diferente de problemas. $.02 \mathrm{La}$ diferencia entre el deber-ser y el deber-ejemplificar es una diferencia entre una cosa que no posee propiedad alguna y otra que no posee propiedades de cierta clase. En el primer caso, la cosa es peor que una que existe y que tiene cuando menos algunas propie-

50 Acerca de la distinción entre "debe existir" y "debe ejemplificar", véase Robert s. Hartman, "Valor y Razón", Diánoia, 1961, pág. 94, nota al calce. Los juicios subyacentes de la proposición axiológica mixta " $x$ debe existir" son " $x$ existe", " $x$ no existe" y " $x$ puede o puede no existir", dependiendo de que la proposición sea axiológicamente analítica, sintética o hipotética.

51 Distinciones similares pueden hallarse a lo largo de los textos de la axiología formal y de la axiología material de Hall. Así, las cuatro proposiciones desconcertantes de Hall: "'Sea cierto o no. que Juan todavía la ama, ciertamente sería bueno si fuera cierto.' 'Debería ser el caso que todo hombre bueno fuera feliz; desgraciadamente, es falso.' 'Hay espías entre nuestros grandes científicos' resulta ser falso; debería: haber sido cierto.' 'Debería ser el caso que todos los sospechosos fueran arrestados; me alegra informar que ése es el caso". (What Is Value?, p. 242) son , ejemplos de proposiciones de "debe" respectivamente hipotética, sintética, sintética y analítica. Sus formas son: $A \leftrightarrow C ; A \leftarrow C ; E \leftarrow C ; A \rightarrow C$. Compárense esta sencilla notación y su significado en la axiología formal con las torturadas -como dice él, "ridículas", "intolerables"- sugestiones de Hall.

52 Véase arriba, nota al calce 50. 
dades ("es mejor para $x$ existir que no existir" o " $x$ debe existir")..$^{.3}$ En el segundo caso, la cosa no es un miembro de una clase particular sino de otra clase y, por tanto, debe ejemplificar a la otra clase y no a la primera; pero debe hacer tal cosa únicamente si la segunda clase tiene más propiedades que ejemplificar que la primera. Si éste no es el caso, la cosa no debe ejemplificar a la segunda clase, sino, analíticamente, a la primera. Todo esto se deriva de la definición de "debe" y sus sentidos positivo y negativo."54

Ahora nos estamos preparando para examinar el problema de la simbolización en general y en la teoría ética en particular. Como hemos visto, la significación sistemática basada en conceptos sintéticos -que legítimamente podemos llamar simbolización-, implica mayor eficiencia empírica, es dečir, significación -sistemático-empírica, que la significación meramente empírica, basada en conceptos analíticos - cuya simbolización podemos llamar ilegítima-. Desde este punto de vista, la axiología formal acaba de pasar un examen sumamente riguroso, resolviendo un problema que el último tipo de simbolización no pudo pasar. Todo esto revela mucho más que una. mera diferencia entre teorias particulares. Muestra una diferencia fundamental en pensamiento axiológico. En consecuencia, sondeemos ahora hasta el fondo de esta diferencia en simbolización. Encontraremos una notable confirmación de nuestra tesis en el sentido de que son los conceptos sintéticos los que dan eficiencia empírica y lós analíticos los que no la dan. El ejemplo que tenemos ante nosotros resulta tan notable debido al gran párecido entre las dos fórmulas - la de Hall y la nuestra - para la bondad. Sin embargo, la de Hall se basa en conceptos analíticos y la nuestra en conceptos sintéticos; la de Hall se basa en conceptos materiales y la nuestra en conceptos formales; y esta diferencia es la que da su diferente poder a las dos simbolizaciones.

Es sumamente sorprendente que una nóción tan lógica como la de ejemplificación deba ser tan vaga cuando se la pone en forma analítica. Pero, como lo hace en su obra Modern Science and Human Values, retrocede ante la brecha que existe entre las dos maneras de pensar, brecha que es tan angosta y sin embargo tan profunda. Así como en el estudio histórico Hall dijo que "como historiador debo reprimirme",56 ahora se reprime incluso en el estudio analítico y le pide "al lector ser indulgente por lo que toca a formulaciones especificas". ${ }^{57}$ Una vez más, Hall ve la cuestión, pero no la ataca con la consecuencia necesaria. Así como dice en el estudio histórico que lo que hace falta es una reforma galileana de la teoría del valor $y$, aunque analiza en detalle el procedimiento galileano en la cien-

53 La estructura del valor, págs. 240 ss.

54 Op. cit., págs. 241 ss.



56 Modern Science and Human Values, pp. 469 ss.

57 What Is Value?, p. 180 . 
cia, no deriva las consecuencias para la teoría del valor; de igual manera dice aquí que "cuando pronunciamos una oración predicativa de valor estamos diciendo algo muy complejo en lo que parece ser una oración simple, algo cuyo análisis requiere una cuidadosa consideración del contexto total y una expansión de la oración analizada en varias oraciones".58 Con todo, Hall no da este patrón de oraciones que una proposición de valor presenta, como lo hace la axiología formal en detalle sobre la base de su axioma. ${ }^{59}$ Una razón de esto es que Hall ha hecho una elección errónea en lo que toca al axioma: ha escogido "debe" en vez de "bueno" como base de su teoría y ha contaminado así con la corrupción del "debe" 60 una versión tan correcta como es su fórmula para " $a$ es bueno" y " $A$ es bueno". Pero la razón principal de su fracaso es su comprensión analítica y no sintética, material y no formal, de la "ejemplificación". Hall es, por así decirlo, el Tico Brahe de la axiología como Moore es su Kepler.61 Tico Brahe se aproximó enormemente a la noción kepleriana y tuvo todo el material empírico en la punta de los dedos, pero no dio el último paso de imaginación sintética.62 Asimismo, sólo un paso es necesario para convertir las conjeturas de Hall en axiología científica: tomar el término "ejemplificación" de manera lógicamente seria: "El que $a$ ejemplifique a $X$ significa que $a$ es un miembro de la clase de $X " .63$. Una vez que se hace esto, todo lo demás se deriva en consecuencia; se hace clara la conexión con la expresión de Moore sobre las "dos proposiciones diferentes [que] son a la vez verdaderas acerca del bien"; y la teoría de la axiología se convierte en un eslabón en el curso histórico de la filosofía moral; y no una serie de adiciones ad hoc.

Asi, pues, no importa cuán aproximado llegue a ser el pensamiento analítico al pensamiento sintético, la brecha sigue siendo infinita y sólo puede salvarse de un salto. ${ }^{65}$ No importa cuán aproximado sea, el pensamiento analítico nunca puede llegar a formular un sistema lógico. Una falla aquí es siempre una gran falla. No importa cuán "lógicas" sean tales formulaciones, a menós que sean verdaderamente lógicas, es decir, sintéticas o axiomáticas, han de seguir siendo arbitrarias e ineficièntes. Un simbolismo pro-

58 Ibid.

60 La estructura del valor, págs. 43 ss., 226 ss.

60 Véase sobre la "falacia normativa" La estructurá del valor, págs. 172, 182, 249, 253, 27 .

61 Véase La Estructura del valor, págs. 221 ss.

62 Tico, dice Goethe (Farbenlehre, Historischer Teil, Fünfte Abteilung), "era una de esas mentes que, por decirlo así, andan de puntas con la naturaleza y; por tanto, aman la paradoja complicada más que la verdad sencilla; 'y se gozan en' el error porque les da una oportunidad de exhibir su perspicacia. Sin embargo, quien reconoce lo verdadero parece honrar a Dios y a la naturaleza, pero no a sí mismo; y de éstos era Kepler".

63 Véase Robert S. Hartman, "Value, Fact and Science", en Philosophy of Science, XXV, (abril de 1958), pág. 108, nota al calce 18.

64. Véase Là estructura del valor; págs. 41 ss., 273 .

65 Op. cit., págs. 134 ss. 
puesto sobre una base analítica, no es pues un instrumento lógico legítimo. Más bien, la próposición de un simbolismo a base de conceptos vagos del sentido común es el meollo mismo de lo que el propio Hall señala como precientífico o, después de la creación del método científico, seudo-científico.

Proponer tal simbolismo no es, entonces, un asunto trivial sino un error fundamental en el pensamiento axiológico. Es tan ilegítimo como lo son, desde el punto de vista moderno, los intentos de hacer oro por parte de los alquimistas. Ellos también iban a tientas de un caso a otro caso, sobre la base del lenguaje cotidiano y lá observación del sentido común. Dado que este procedimiento de seudo-simbolismo se utiliza ampliamente en la filosofía moral en nuestros días, debemos examinarlo en detalle. El procedimiento de Hall es sólo un ejemplo de una práctica frecuente.

\section{Taquigrafía analitica y simbolismo sintético}

Puede decirse que la tesis fundamental de Hall consiste en la separación de la estructura del hecho y la del valor, respectivamente, en la estructura de las oraciones declarativas y normativas. Esto significa que la realidad, ya sea hecho o valor, aparece en la estructura del lenguaje cotidiano y sus conceptos analíticos. Pero, como hemos visto, éste no es el caso. La realidad correspondiente a los conceptos analíticos no es en modo alguno la del hecho; es la de un espejismo desfigurado del mundo. Es el mundo de los hechos sensoriales, y estos hechos varían con la estructura conceptual del lenguaje. El verdadero hecho científico aparece únicamente como concomitancia de los sistemas sintéticos. Así, pues, cuando menos, la eștructura del hecho y su relación con el lenguaje son más complejas de lo que Hall supone. Pero entonces también la relación entre el valor y el lenguaje debe ser más compleja, y debe haber una diferencia entre el valor según aparece en la estructura del lenguaje analítico y en la estructura del lenguaje sintético. Así, pues, del mismo modo que en Modern Science and Human Values ni el hecho, ni la ciencia ni el valor fueron definidos, el examen en What Is Value? adolece de ùna fundamental vaguedad y falta de definición de los términos. Por lo menos hay dos clases de hecho y dos clases de valor: aquellos que pertenecen a y se derivan del lenguaje analítico, tales como "Juan se está cayendo por las escaleras" y "Juan es bueno"; y aquellos que pertenecen a y se derivan del lenguaje sintético, tales como " $a=1 / 2 \mathrm{gt}^{2 "}$, que es la fórmula en la mecánica que Juan ejemplifica cuando se cae por las escaleras, y "bueno $=(\varphi)$ $\varphi \omega \Phi D)$." que es la fórmula de la axiología formal que él ejemplifica al ser bueno, es decir, al tener todas las propiedades contenidas en su concepto de sí.66 Esta segunda clase de hecho y de valor no puede" aparecer, obviamente, en el lenguaje ordinario.

0.6 Op. cit., págs. 228 ss. 
Así, en virtud de su supuesto fundamental, Hall sè aparta de la comprensión sistemática de la realidad del valor, y se limita a fenómenos del valor secundarios y del sentido común. $Y$, sin embargo, sobre la base de este tipo analitico de comprensión, Hall propone un simbolismo. Examinemos ahora la naturaleza de tal simbolismo. Obviamente no se deriva, como el de Galileo, de la comprensión perspicaz del fenómeno, pues a Hall no le interesa el fenómeno; le interesa lo que la gente dice acerca de éste en el lenguaje ordinario del valor. Ésta, por supuesto, es la clase de procedimiento wittgensteiniano. ${ }^{67}$ Hall presupone que ciertas afirmaciones que las personas hacen son afirmaciones de valor $\mathrm{y}$, por tanto, la estructura de tales afirmaciones es pertinente a la estructura del valor. Hall, pues, toma el lenguaje de las personas ordinarias como su guía filosófica, en lugar de penetrar por sí mismo en la naturaleza del valor, descubriendo una estructura en ella y aplicando esa estructura $a$ lo que las personas dicen, operando como guía de ellas y no permitiendo que ellas lo guíen a él. Así, en lugar de preguntarse; con toda seriedad, "¿Qué es el valor?", Hall se pregunta "¿Qué se dice acerca del valor?" Su procedimiento es precisamente igual al que caracteriza como alquímico: observa las propiedades secundarias de los fenómenos como si fuesen primarias, y deriva de ellas toda clase de conclusiones, como si fuesen conclusiones acerca del fenómeno y no acerca de cómo el fenómeno se aparece a, y dentro de, el mundo de la experiencia. Hall incluso llega a sugerir un simbolismo para estas apariencias. Veamos qué significaría históricamente este procedimiento.

Supongamos que Galileo hubiese intentado "llegar a" 68 la naturaleza del movimiento a través de la estructura de las oraciones del movimiento. Él hubiera tenido, en otras palabras, que recoger muestras de oraciones del movimiento pronunciadas por personas en y acerca del movimiento, $y$ analizar su estructura. Pues, de acuerdo con Aristóteles, el movimiento de la gente es tan pertinente a la naturaleza del movimiento como el de las piedras, pongamos por caso. En lugar, por tanto, de tomar el camino difícil y tratar de entender el lenguaje de las piedras -como lo hizo-, Galileo pudo haber tomado un camino más fácil y escuchado el lenguaje de la gente. No había ni más ni menos razón para que él escuchara el lenguaje de las piedras en vez del de la génte, que la que hay para que los axiólogos escuchen el lenguaje de la gente y no el de las piedras. Tanto la gente como las piedras se mueven, y tanto la gente como las piedras tienen valor -especialmente las "piedras preciosas". No es obvio, por tanto, que el lenguaje de valor de la gente sea más revelador de la naturaleza del valor que el de las piedras. Pero es más fácil de escuchar.

Supongamos ahora que Galileo, después de escuchar las oraciones de la

67 Op. cit., págs. i6o ss.

68 Véase arriba, pág. 74. 
gente sobre el movimiento, hubiese analizado la estructura de esas oraciones y hubiese propuesto un simbolismo paralelo al de la lógica de Aristóteles; y en lugar de escribir "S es $\mathrm{P}$ " hubiese escrito, siempre que se hubiera tratado de una cuestión de movimiento, "S es $\mathrm{K}$ ", introduciendo así el predicado cinético $\mathrm{K}$; de modo que "S es $\mathrm{P}$ " representara, por ejemplo, "Sócrates es un hombre" y "S es K." "Sócrates es un bípédo"; y que él hubiese propuesto esta nueva notación como un "programa" para la solución del problema del - movimiento y derivado toda clase de consecuencias, por ejemplo el paralelismo entre Barbara y $K \cdot$ Barbara, Celarent y $K$-Celarent, Darii y $K$-Darii, etc., observando quizá que Santa Bárbara es la santa patrona de los artilleros, - que están en constante movimiento y lanzan proyectiles, que "celer" quiere decir "rápido", que "celarent" es el uso corriente del condicional contrario al hecho "celerarent", que significa un movimiento tan rápido que no existe $\mathrm{y}$, por tanto, es invisible $\mathrm{y}$, por tanto, el más rápido posible; ${ }^{69}$ que, de acuerdo con Herodoto, la carroza de Darii era la más rápida de todas - todo lo cual, hubiese concluido Galileo, hace obvio el hecho de que K-Barbara, $\mathrm{K}$-Celarent y K-Darii son movimientos válidos de la primera figura $\mathrm{K}$, etc. Semejante procedimiento alquímico, basado firmemente en el sentido común y el lenguaje ordinario, no hubiera conducido a los sistemas de Newton y Einstein. No hubiera respondido a la pregunta ¿Qué es el movimiento? Lo que hacia falta era un sistema que descartara completamente al sentido común y se basara en una nueva comprensión profunda del fenómeno mismo, como el propio Hall hace tan meridianamente claro en Modern Science and Human Values. ${ }^{70}$

Supongamos, entonces, que Hall tiene razón y que el valor es el fenómeno que debe investigar la teoría del valor, del mismo modo que la mecánica tuvo que investigar el movimiento. Entonces, un procedimiento como el ya mencionado no sería más significativo en la teoría del valor que lo que habría sido en la mecánica. Con todo, ése es precisamente el procedimiento de Hall. En notación lógica moderna, " $A(a)$ " representa " $a$ ejemplifica a $A$ ". Hall reemplaza "( $)$ " por " \{\} " y propone la nueva notación $A\{a\}$, " $a$ "debe ejemplificar a $A$ ", como una contribución significativa a la comprensión de la naturaleza de "debe". $\mathrm{Y}$, con toda seriedad, se producen discusiones acerca de los méritos y deméritos de este simbolismo, bajo títulos como "La naturaleza de "debe" "; 71 y se abordan con él problemas axiológicos reales, como hemos visto.

Sin embargo, dado que la teoría subyacente carece de precisión de pensamiento y que su autor admite hallarse en la oscuridad por lo que se refiere a la naturaleza del valor, su sustitución de " ( )" por " $\{$ Y" en la fórmula de

69 Para un perfeccionamiento moderno similar de los logros alquímicos véase E. $\mathbf{T}$. Bell, The Magic of Numbers, McGraw-Hill Co., New York, 1946, pág. 177.

70 Págs. 22 ss. Véase La estructura del valor, pág. 214.

71 E. M. Adams, Philosophical Studies, VII, pp. $3^{6-42}$ (abril de 1956). 
ejemplificación tampoco puede significar nada preciso. Está basada en una corazonada: que la estructura del valor aparece en la estructura de las oraciones de valor y que esta última es "paralela" a la de las oraciones de hecho. Este procedimiento, pues, no tiene mayor justificación que el de nuestro Galileo silogístico, basado en la corazonada de que la estructura del movimiento aparece en la estructura de las oraciones de movimiento y que la estructura de tales oraciones es "paralela" a la de las oraciones de no-movimiento, de donde se deriva su sustitución de "K" por "P". En. ambos casos, el instrumento de precisión de la lógica se utiliza sobre la base de una corazonada, fortalecida por una metáfora - la del "paralelismo"- y semejante utilización de un instrumento de precisión difícilmente puede ser algo más que un juego de palabras. ${ }^{2}$ Utilizar tal instrumento sobre una base tan vaga, es utilizarlo ciertamente en una forma contraria a su naturaleza; es una utilización ilegítima del simbolismo.

Esto es mucho más serio de lo que podría parecer. Lejos de ser "valioso", como piensa Hall,73" semejante "simbolismo arbitrario" "7a es, por el contrario, nada valioso y sí perjudicial a la causa del conocimiento exacto, pues pretende ser lo que no es, a saber, un instrumentó de precisión; ocultando así la naturaleza de un verdadero instrumento de precisión: su empleo exclusivo al servicio de los conceptos sintéticos. En la medida en que un simbolismo arbitrario, basado en conceptos analíticos, se toma en serio, se oscurece la concepción de los verdaderos instrumentos de precisión y se disfraza la naturaleza alquímica del procedimiento. Tenemos aquí, pues, una fundamental falta de comprensión de la propia empresa del conocimiento, que no puede sino obstruir los esfuerzos para crear un instrumento de precisión para el pensamientó ético. Esta falta de comprensión debe ser considerada con toda la seriedad que se merece.

La falta fundamental de comprensión radica en el supuesto de que se puede simbolizar algo que no se conoce. Esto es como usar una lámpara eléctrica en lugar de un faro. ${ }^{\mathbf{7 5}}$ En lugar de construir lenta y pacientemente, sobre la base de la perspicacia fenomenal, círculos de pensamiento cada vezmás altos y más estrechos, hasta completar la estructura del faro y poner la señal luminosa en la parte superior, este procedimiento es como jugar en la playa, tomando unos cuantos guijarros aquí y allá, y luego, sin ninguna conexión orgánica con el problema y sobre la base de vagas analogías y paralelismos, encender una lámpara eléctrica y darle el nombre de faro.

El procedimiento legítimo debe estar basado en un supuesto contrario al que parece hallarse en la base de los empeños simbólicos de Adams, Hall y otros similares: que no se puede simbolizar lo que no se conoce. De lo que

72 Véase más adelante, nota al calce 76 .

73 What Is Value?, p. 183 .

74 Ibid.

75 Véase La estructura del valor, pág. 125 ss. 
no se puede hablar, se debe guardar - en símbolos- silencio. La razón es, simplemente, que un simbolismo no puede decir más de lo que se ha puesto en él. Si no se pone nada significativo en él, el simbolismo no puede dar nada significativo a su vez; y sólo puede vagar cómo un motor que no va a ninguna parte. La "perspicacia" analítica carece formalmente de valor. Y cualquier simbolismo basado en ella es, a lo sumo, taquigrafía. De tal suerte, la sustitución de paréntesis por corchetes, que hace Hall, no es lógica sino taquigrafía. Tal taquigrafia no es más significativa para la naturaleza del valor que los signos del Zodiaco para las estrellas. Está tan lejos de la axiología verdaderamente formal como la astrologia de la astronomía.

Resulta que esto, tan obvio en la ciencia natural, sea oscuro en la ciencia moral y social. En ésta, la verdadera significación de tales ejercicios seudo-teóricos es puesta al descubierto no por los científicos morales o sociales, sino por los científicos naturales, adiestrados en los métodos formales génuinos y sus aplicaciones. ${ }^{76}$ En todos los casos, tales métodos genuinos se basan en una perspicacia original, perspicacia formal o sintética que penetra en el propio fenómeno. Sólo cuando se ha alcanzado tal perspicacia, puede un simbolismo ayudarnos y darnos alas. Sin tal perspicacia previa, el simbolismo es tan dañino como útil es con ella. En el primer caso nuestras alas son plumas, y el axiólogo es un fcaro que ciertamente arderá bajo el sol de Platón. En el segundo caso, nuestras alas son poderosos motores, y el axiólogo un Lindbergh que atraviesa espacios desconocidos.

Un simbolismo analítico como el de Hall o el de Adams $\rightarrow$ de los autores mencionados en la nota al calce 6- nunca tendrá buen éxito; ni lo tendrá tampoco ningún intento de manipulación simbólica en que se reconozca la ausencia de comprensión perspicaz del fenómeno. Esta severa conclusión, que es obvia sobre la base de nuestra distinción entre el conocimiento analítico y el sintético, la ilustraremos ahora, primero con un ejemplo contemporáneo y después con un ejemplo histórico real, no imaginario.

En la actualidad no sabemos nada acerca de los platillos voladores. Supongamos que aceptamos el supuesto de que el lenguaje relativo a los platillos voladores revelaría la naturaleza de éstos. Reuniriamos entonces todas

76 Cf. la crítica que hace $\mathrm{E}$. T. Bell de una conocida teoría sociológica. Todo lo que dice Bell sobre la utilización de las "matemáticas" en la teoria en cuestión, es aplicable a la utilización de la "lógica" en la axiología material de nuestro tiempo: "No existe una incomprehensión más patética de la naturaleza y función de las matemáticas que el trillado cliché de que las matemáticas son una taquigrafía... La mera simbolización de cualquier disciplina no es ni siquiera una parodia respetable de las matemáticas... La teoría $S$ tiene todavía que dar su primer paso hacia cl simbolismo matemático generativo... Ningún abuso atolondrado del vocabulario matemático puede [por sí] transformar una teoría que todavia no es matemática en algo más sustancialmente matemático que un endeble juego de palabras matemático... No hay matemáticas en el libro”. E. T. Bell, reseña de S. C. Dodd, "Dimensions of Society", en Amer. Sociol. Review, VII, págs. 707-9 (1942). Sobre la naturaleza lógica del simbolismo taquigráfico, véase Juan David García Bacca, Introducción a la lógica moderna, Editorial Labor, Barcelona, 1936, págs. 37 ss. 
las oraciones que han sido pronunciadas acerca de los platillos voladores, destilaríamos de ellas su estructura lógica, expresaríamos esta estructura en algunos símbolos y operaríamos con esos símbolos como si estuviésemos operando con la estructura de la naturaleza de los platillos voladores. Obviamente, no se nos tomaria en serio.

El mismo procedimiento, cuando se aplica al valor -acerca del cual tampoco sabemos nada--, se considera plausible.

Demos un paso adelante. Estáis errados, se nos podría decir, los platillos voladores tienen una estructura muy intrincada, que no puede ser descubierta en el lenguaje ordinario cotidiano, sino en el de las ecuaciones matemáticas. Es preciso que formuléis esas ecuaciones, y entonces sabréis qué son los platillos voladores. Esto, por supuesto, es un gran avance; pero no nos hace adelantar gran cosa, pues coloca el carro delante de los caballos. Indudablemente, la naturaleza de los platillos voladores será revelada por la estructura de las ecuaciones que los explican. Podemos así, muy plausiblemente, definir un platillo volador como aquello que hace que una ecuación de platillo volador legítima, sea legítima. Pero, ¿podrá el uso de reglas semánticas en el lenguaje ideal de los platillos voladores - la matemática aplicada, pongamos por caso- ayudarnos a adquirir una comprensión perspicaz de los platillos voladores? Hall cree, en el caso paralelo del valor, que "con muchas reservas, hasta cierto punto sí puede ayudarnos". ${ }^{77}$ Obviamente, sin embargo, no puede. Pues, ¿cómo podría yo saber que cierta estructura - cierto conjunto de ecuaciones diferenciales, por ejemplo- se refiere a los platillos voladores, si no sé qué son. los platillos voladores? Primero debo saber de qué estoy hablando, antes de poder hablar acerca de ello, mucho más si es en sentido técnico.

El caso del valor no puede ser diferente. Primero debo saber qué es el valor, antes de poder hablar acerca de él, mucho más si es en lenguaje técnico. ¿Cómo sabría yo que cierta estructura de oraciones - las normativas, digamos- se refiere al valor si no sé qué son los valores? El suponer que la estructura del valor resplandece a través de la estructura de ciertas oraciones, no es ni más ni menos justificado que el suponer que la estructura de los platillos voladores resplandece a través de la estructura de ciertos conjuntos de ecuaciones diferenciales.

Consideremos ahora el ejemplo histórico real. Platón sabia muy poco acerca de la constitución de la materia. Sin embargo, los pitagóricos habían mostrado que los números triangulares $1,3,6,10,15,21$, etc. —números que podían ser representados en formas de triángulos_- 78 tenían propiedades muy

77 What Is Value?, p. 226 
peculiares. Especialmente el cuarto de ellos, el 1o; no sólo era un triángulo, sino también la suma de los números triangulares precedentes. Por tanto, era el tetractys sagrado, el cuarto número triangular sagrado, en el que están contenidas todas las cosas. Obviamente, en consecuencia, era el patrón arquetípico del universo. A partir de él, y a partir de la serie triangular en general, podían generarse los cuatro elementos - füego, aire, tierra y agua - y podían ser representados en términos de los cuatro sólidos regulares conocidos: el fuego como el tetraedro, el aire como el octaedro, la tierra como el hexaedro (o cubo) y el agua como el icosaedro. Y puesto que "el mundo debe ser sólido", como leemos en el Tímeo, era una cuestión de sentido común ${ }^{79}$ para Platón que la estructura dei luniverso estaba revelada en la estructura de los números triangulares. ${ }^{80}$ No hay ninguna razón para que esto no haya, debido ser así para Platón, pues él- sabía acerca de la estructura de los números triangulares más o menos tan poco como lo que sabía acerca de la constitución de la materiạ; y se puede decir cualquier cosa acerca de lo que no se.sabe, especialmente algo sobre lo que uno sabe igualmente poco.

-Una vez más, esto es exactamente análogo al procedimiento de Hall. Existe tanta o tan poca razón para la creencia de Hall de que la normatividad esencial del valor y su estructura resplandecen a través de la estructura de las oraciones normativas, como la había para la creencia de Platón de que la "triangularidad esencial" de la materia y su estructura resplandecían a través de la estructura de los números triangulares. Ciertamente, la conjetura de Hall sería ingeniosa si tuviera tanta plausibilidad como la de Platón. Pues, siguiendo las pistas pitagórico-platónicas, Kepler descubrió la primera y segunda leyes de las órbitas planetarias. Es cierto que lo hizo sobre la base de los industriosos materiales empíricos de Tico Brahe; y fue esta base fenomenal la que le permitió triunfar donde Platón y otros numerólogos -aquellos que usaron el número sin base empírica- habían fracasado. De èsto podemos concluir que una base fenomenal similar puede dar pertinencia valorativa a los empeños de nuestros logicólogos modernos - aquellos que usan la lógica sin base empírica-. Por otra parte, es preciso recordar que los fenómenos a menudo no son visibles, excepto para quien los busca; y sólo puede buscarlos eficazmente, quien tenga el marco teórico correspondiente. Aunque todos los fenómenos de la vida moral se encuentran a nuestro alrededor, si carecemos del marco teórico comprehensivo sólo vemos porciones aisladas, y nuestros tratados de ética, en vez de darnos el drama moral de la

79 Timeo, $56 \mathrm{~B}$.

80 En tiempos de platón, el quinto sólido, cl dodecacdro, ya había sido descubierto. Antes que arruinar la cuádruple armonía de los elementos, Platón encarecía al demiurgo que "la utilizara para bordar los cielos de constelaciones" (Timeo, $55 \mathrm{C}$ ). El quinto sólido, en vez de ser otro elemento material, vino a ser la "quintaesencia" que regula el todo. Keplér hizo un uso impresionante de todo ésto, tomando el dodecaedro como símbolo de los doce signos del Zodiaco $y$, así, del universo mismo. 
época, ${ }^{81}$ están llenos de pequeñas anécdotas insignificantes y ejemplos vacuos del uso de imperativos, normativos, etc., que son o bien trillados - "Sed caritativos"- o bien triviales - “Agítese antes de usarse"-.. Éstos se hallan lejos de ser siquiera keplerianos. Y los descubrimientos de Kepler vinierón a ser significativos sólo después de haber sido combinados con las minuciosas investigaciones empíricas de.Galileo, dentro del sistema empírico-teórico de Newton. Hay, pues, un largo trecho por recorrer para que los esfuerzos logicológicos -o logológicos - sean moralmente pertinentes... si alguna vez llegan a serlo. Pues la mayor parte de la numerología -simbolismo matemático sin base fenomenal - siguió siendo estéril e insignificante para el desarrollo de la ciencia. Resulta difícil ver por qué el caso habría de ser diferente con la logología — simbolismo lógico sin base fenomenal- en el desarrollo de la ciencia del valor.

La diferencia entre la numerología o la logología y la genuina construcción de sistemas es, entonces, que en la segunda existe una base fenomenal que se expresa sistemáticamente en símbolos, mientras que en las primeras la base fenomenal, y en consecuencia su expresión simbólica en una teoría consecuente, están ausentes. Tales símbolos no son, entonces, nada más que símbolos, porciones aisladas de notación fuera de toda matriz sistemática: jirones de niebla que se nos ofrecen como pedazos de tela: No es posible resolver, mediante la mera notación, problemas fundamentales en la filosofía moral, como tampoco es posible resolver de esta manera problemas fundamentales en la filosoffa natural. Pero, en tanto que los alquimistas no contaban con antecedentes y tenían que recorrer su camino a ciegas, nosotros sí tenemos un antecedente: a saber, los alquimistas negativamente y sus sucesores científicos positivamente. Nuestro intento debe seguir el ejemplo de esos sucesores. Según existe en la actualidad, la filosofía moral sigue, metodológicamente, los procedimientos de los alquimistas y los astrólogos; y nuiestros símbolos logológicos no tienen mayor pertinencia para el valor que los símbolos alquímicos para la materia o los astrológicos para las estrellas.

Fueron necesarios Galileo y Lavoisier para superar este tipo de pensamiento. Ellos lograron la superación mediante el descubrimiento, en los propios fenómenos, de las propiedades primarias que los hacen accesibles a la notación formal. Antes de ellos, las matemáticas se utilizaban al azar; y el procedimiento alquímico y astrológico bien podría definirse como la utilización al azar de las matemáticas aplicadas a los conceptos analiticos. Galileo y Lavoisier hicieron claro que el instrumento de precisión de las matemáticas sólo puede utilizarse legitimamente cuando la disciplina en cuestión ha sido preparada para su utilización. Los alquimistas.y los astrólogos, entonces, utilizaron el número prematuramente. $\mathrm{Y}$ tal utilización prematura de un instrumento de precisión es el procedimiento típico de la seudo-ciencia; es

81 La estructura del valor, pág. 158. 
como el bisturí sin el conocimiento anatómico. Es charlatanería metodológica, sólo que el cuerpo que la sufre en nuestros días es el cuerpo político más bien que el cuerpo físico, como en los tiempos de Paracelso. El formalismo, entonces, no es ningún juguete; es una cosa seria. $Y$ su utilización sin la preparación de la disciplina en cuestión no es menos irresponsable en la filosofía moral de lo que lo fue en la filosofía natural. No estamos sólo en la época de los alquimistas morales, sino también de los barberos morales.

*Así, pues, ningún uso de las matemáticas es legítimo sino la aplicación a las propiedades primarias. Allí donde los fenóménos en cuestión no sean "resueltos" —en el sentido galileano- en tales propiedades, la utilización de las matemáticas es un juego ocioso. No se puede utilizar legítimamente el número sin antes haber penetrado en la esencia de aquello que los números suponen representar.: No puede haber isomorfismo entre los fenómenos y el simbolismo a menos que haya morphé fenomenal.

Lo que fue cierto en el caso de la filosofía natural, debe serlo en el caso de la filosofía moral. Las notaciones formales, ya sean numéricas o de símbolos lógicos, pueden ser aplicadas al valor sólo si el propio fenómeno de valor ha sido resuelto en propiedades primarias y definido en términos formales. Tal definición, por supuesto, tal penetración hasta la médula misma del fenómeno debe ser la verdadera labor del axiólogo, como siempre ha sido la del físico y la del químico. Sin esa penetración feriomenal, cualquiera utilización de la notación formal es un intento de recoger la cosecha sin haber sembrado la semilla: un procedimiento fundamentalmente erróneo e ilegítimó. Así, pues, se hace-inevitable concluir que cualquiera utilización de la notación formal con referencia al valor -a menos que se sepa qué es el valor en el sentido de haber descompuesto el fenómeno en sus propiedades primarias accesibles a tal notación-, es un juego estéril. Sólo cuando se ha ofrecido una definición del propio fenómeno de valor en términos lógicos, puede utilizarse con alguna probabilidad de éxito la notación formal. Ésta sólo puede utilizarse, entonces, dentro de una teoría formal total del valor; y rio sin ella o fuera de ella. Primero hay que construir el modelo lógico, la "lógica en miniatura" que explique el valor, del mismo modo que Galileo construyó el modelo geométrico, la "geometría en miniatura", que explicó el movimiento. ${ }^{82}$ Es esta clase de modelo lógico el que se ha estado tratando de construir en la axiologia formal.

La situación actual en la filosofia moral es, como en muchos otros aspectos, con respecto a la naturaleza simbólica del valor, precisamente análoga a la situación correspondiente en la filosofía natural. No faltaron, desde luego, críticos de los juegos algorítmicos de los seudo-filósofos de la naturaleza, no sólo aquellos que, como Galileo, sabían la solución corréecta, sino también aquellos como Francis Bacon, que no la sabían, pero la adivina-

82 E. W. Hall, Modern Science and Human Values, pp. 105 ss. 
ron. Bacon expuso, contra los intentos de sus colegas naturalistas de omitir la etapa empírica, exactamente las mismas objeciones que nosotros exponemos.

Obviamente, el procedimiento de aplicar símbolos lógicos, al valor, es útil para la valoración sólo si la valoración es una cuestión de la lógica. Si lo es y cómo lo es, debe ser el primer problema que examinen los axiólogos antes de aventurarse a proponer un simbolismo del valor. Fue, precisamente, la utilización prematura de los instrumentos de precisión - ya fuera la lógica aristotélica o las matemáticas platónicas o, en general, cualquier separación de la teoría y la práctica- lo que Bacon objetó. ${ }^{83}$ Su caracterización de la situación en la filosofía natural de su tiempo es bien aplicable a nuestra situación en la filosofía moral. Quienes han manejado la axiologia "han sido o bien experimentadores o bien dogmáticos: Los experimentadores son como la hormiga: sólo recolectan y usan; los razonadores se parecen a las arañas, que hacen sus telas de su propia sustancia. Pero la abeja toma un camino intermedio: extrae su material de las flores del jardín y del campo, pero lo transforma y lo digiere mediante su propio poder. Similar a esto es la verdadera tarea de la filosofía, pues ni depende única o principalmente de los poderes de la mente, ni tampoco toma el material que extrae de la historia natural y de los experimentos mecánicos y lo acumula en la memoria, conforme lo encuentra, sino que lo acumula en la comprensión ya alterado y digerido. Por tanto, es dable poner muchas esperanzas en una liga más íntima y más pura entre estas dos facultades, la experimental y la racional (lo que nunca se ha hecho hasta ahora)". ${ }^{84}$ No existe aún ninguna "liga" como ésta en la filosofía moral, por la doble razón de que el material empírico no ha sido reconocido y el marco teórico no ha sido creado. Lá mayor parte de los axiólogos de nuestro tiempo son hormigas o arañas, o ambas cosas: saltan de los materiales seudo-empíricos -el vocabulario popular del hombre de la calle- a conclusiones seudo-racionales. Ésta es, precisaménte, la contorsión de la "experiencia" y, por tanto, del pensamiento, a que se refería Bacon: "Hombres de saber, pero también ociosos y cómodos, han tomado para la construcción o para la confirmación de su filosofía, ciertos rumores y vagas famas o aires de experiencia, y han concedido a éstos el peso de la evidencia legitima. $Y$ al igual que si algún reino o estado fuese a tramitar sus concilios y sus asuntos, no a base de las cartas y los informes de los embajadores y mensajeros de confianza, sino de los rumores de la calle, asi exactamente es el sistema de tratamiento introducido en la filosofia en relación con la experiencia. Nada debidamente investigado, nada verificado, nada 'con-

83 Novum Organum, Libro I, Aforismo XCV ss. Bacon nunca comprendió la diferencia entre esta utilización ilegítima de las matemáticas y la utilización legítima por parte de Copérnico y Galileo. Ninguno de éstos era como la hormiga empírica o la araña dogmática; pero si eran, especialmente Galileo, como la abeja industriosa y, creadora de forma (Aforismo XCV).

84 Op. cit., Aforismo XCV. 
tado, pesado o medido, es dable hallar en [la axiología]; y lo que en la observación es vago e inconexo, en la información es engañoso y traicionero". 85 Lo que es investigado, verificado, contado, pesado o medido no es nada pertinente al asunto - el valor-, o cuando menos esta pertinencia no se investigá. De tal suerte, "no tenemos hasta la fecha ninguna filosofía [moral] que sea pura; todo está contaminado y corrompido: en la escuela de Aristóteles por la lógica, en la de Platón por la teología natural, en la segunda escuela de los platónicos, tales como Proclo y otros, por las matemáticas, que sólo deben dar carácter definido a la filosofía natural, no generarla o darle origen. De una filosofía [moral] pura y libre de mezclas, è dable esperar mejores cosas. Todavía no se ha encontrado a nadie con tal firmeza de mente y de propósito que se resuelva a barrer con todas las teorías y nociones comunes y a aplićar lá comprensión, ya justa y serena, a un nuevo examen de los particulares. Así, sucede que el conocimiento [moral], según existe ahora, no es más que una masa desigual y mal digerida, compuesta de mucha credulidad y mucho accidente, y también de las nociones pueriles que en nuestros primeros tiempos adquirimos".86 Fue esta clase de método la que condujo, poŕ una parte, a los juegos numéricos de los adversarios escolásticos de Galileo y, por otra, a las maquinaciones de los herméticos.

Hoy afrontamos exactamente los mismos peligros de extraviarnos, en la axiología, por cualquiera de estos dos caminos. Por esta razón es de tan fundamental importancia tener claridad acerca de la verdadera dirección: la sustitución de los conceptos analíticos por los sintéticos, de los axiomáticos por los categóricos. De lo contrario, seremos incapaces de abrirnos camino a través de la selva que es la filosofía moral de hoy, llena de las hor- migas que son los empíricos seudo-científicos - desde los positivistas y materialistas hasta los simbolistas logólogos_- y de las arañas del dogmatismo -desde los constructores analíticos de "sistemas" hasta los moralistas teoló. gicos e ideológicos.

Recordemos, como resumen, las famosas palabras de Bacon sobre los axiomas intermedios que todo axiólogo debe recordar antes de remontarse, aun tentativamente, a la estratosfera del simbolismo: "A la comprensión no debe... permitírsele saltar y volar desde los particulares hasta los axiomas remotos y de casi lá más alta generalidad... y, tomando pie en ellos como verdades inconmovibles, proceder a probar y formúlar los axiomas intermedios médiante la referencia a aquéllos; lo cual ha sidö la práctica hasta ahora; habiendo sido llevada la comprensión por ese camino, no sólo por un impulso nátural, sino también por el uso de la demostración silogística entrenada y avezada a tal uso. Pero entonces; y sólo entonces, podremos poner esperanzas en las ciencias, cuando en una justa escala de ascenso y mediante

85 Op. cit., Afórismo XCVIII (cursivas nuestras).

86 op. cit., Aforismo XCVI, XCVII. 
pasos ininterrumpidos y continuos, nos elevemos de los particulares a los axiomas menores; y luego a los axiomas intermedios, uno encima del otro; y por último a los más generales. Pues los axiomas más bajos difieren apenas de la mera experiencia, en tanto que los más altos y más generales (que ahora tenemos) son conceptuales y abstractos y sin solidez".87 Para darles solidez es preciso que sean sintéticos y no analíticos - algo que Bacon no vio claramente - y para ser sintéticos deben estar profundamente anclados en el fenómeno - y esto sí lo vio claramente. Así, de igual manera que los con: temporáneos de Bacon en la filosofía natural trataron de volar antes de saber andar, nuestros contemporáneos en la filosofía moral tratan de pilotar aviones supersónicos antes de resolver las ecuaciones más elementales de la aerodinámica. Su "comprensión no debe ser dotada de alas, sino más bien sujeta con pesas". ${ }^{88}$ Sin embargo, las pesas -y las medidas y las clasificaciones y demás parafernalia empirica- tienen su propio regulador en la axiología. El axiólogo perito tiene que navegar entre los dos peligros del seudologicismo y del seudo-empirismo. ${ }^{89}$

\section{ROBERT S. HARTMAN}

87 Op. cit., Afor: CV. Cf. Goethe: "Saltar, en la reflexión, de lo singular inmediatamente a lo universal es el error de los espíritus débiles." (Naturwissenschaftliche Schriften, Gedenkausgabe der Werke, Briefe und Gespräche), Zürich, 1949, Vol. 17, p. 705.)

88 Bacon, loc. cit."

89 Sobre el último véase Robert S. Hartman, “Axiología y Semántica: un Ensayo sobre la Medición del Valor", Diánoia, 1960. 